\title{
Towards the second stage-Journal of Intensive Care
}

\author{
Hiroshi Morisaki
}

It is my great honor and concurrently challenging task to make this statement as the new Editor-in-chief of the Journal of Intensive Care. To date, this Journal, which was launched in October 2013, as the official journal of the Japanese Society of Intensive Care Medicine (JSICM), has been outstandingly led by Professor Satoshi Gando, the founding Editor-in-chief. Being an international journal, the members of Advisory and Editorial Board embrace many worldwide leaders in the intensive care field. Based on their continuous and persevering efforts, in addition to the enthusiastic contribution by all authors and/or researchers, we are proud of a number of remarkable and significant articles published in the first stage of this newborn journal. In the first 2 years after its launch, more than $55 \%$ of the submissions came from Japanese researchers and/or intensivists; now, almost $75 \%$ of the submissions come from researchers in other areas of the world, including North America and Europe, as well as Asia, Middle East, and Oceania (Fig. 1).

Recently, there has been a notable increase in the number of submissions. Last year, the Journal of Intensive Care received 341 submissions, which amounts to an approximately $35 \%$ increase in comparison to the previous year (Fig. 2). Predictably, the overall acceptance rate is decreased to $21.3 \%$ last year, while $19.7 \%$ of research articles submitted were finally accepted for publication. Furthermore, I dare to declare that we have continued to accept the submission of case reports on cases showing an extraordinary clinical course in which the discussion is informative to the readers; however, the acceptance rate of case reports is currently $7.3 \%$. It should also be noted that the average intervals from the formal receipt of a manuscript to the dates of the first and final decisions were 16.7 and 33.4 days, respectively. Although nobody can conclude whether the current editorial and reviewing processes are short enough to satisfy the authors/researchers, I believe that both highquality reviewing and prompt publication are indispensable for a medical journal. On behalf of the Editorial Board

Correspondence: morisaki@z8.keio.jp

Department of Anesthesiology, Keio University School of Medicine, 35

Shinanomachi, Shinjuku-ku, Tokyo 160-8582, Japan
Members, I would like to express my sincere appreciation to all peer reviewers for their persistent, patient, and noble contribution to this Journal.

Owing to the countless journals that have been launched in the last decade, international journals must now compete with each other within the same field of medicine. By the end of 2017, there were 57 and 137 journals including the term, intensive care and critical care, respectively. To prevail and thereby step forward in these types of struggles between the journals, we must continue to work hard on improving both the academic and clinical quality of this journal by publishing high-quality articles and simultaneously providing more constructive peer-review processes. To date, all articles published in the Journal of Intensive Care are indexed in worldwide services such as DOAJ, PubMed, PubMed Central, and Scopus. Now, based on continuous and overall assessment, our journal has been uploaded on the Emerging Sources Citation Index (ESCI), implying that the journal is close to obtaining Social Sciences Citations Index value (i.e., impact factor).

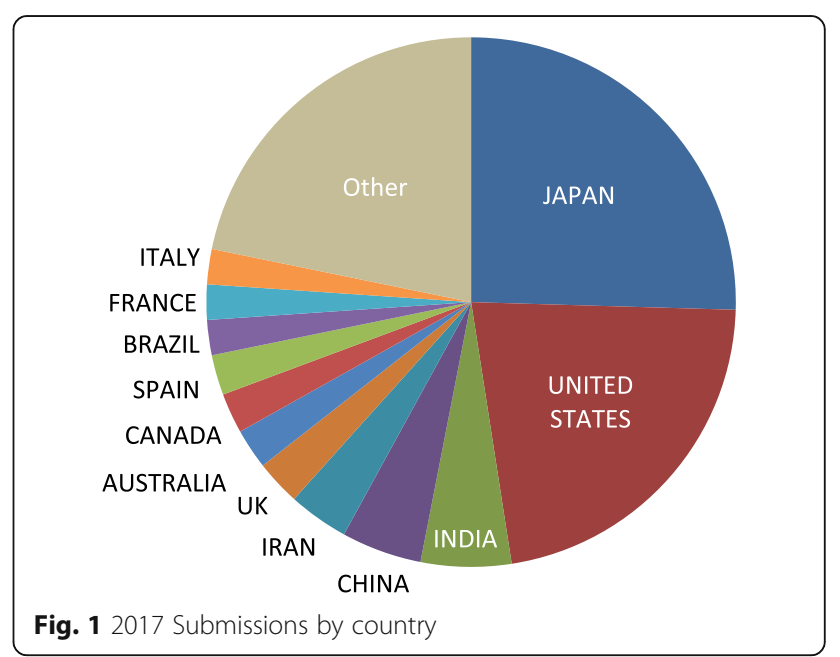




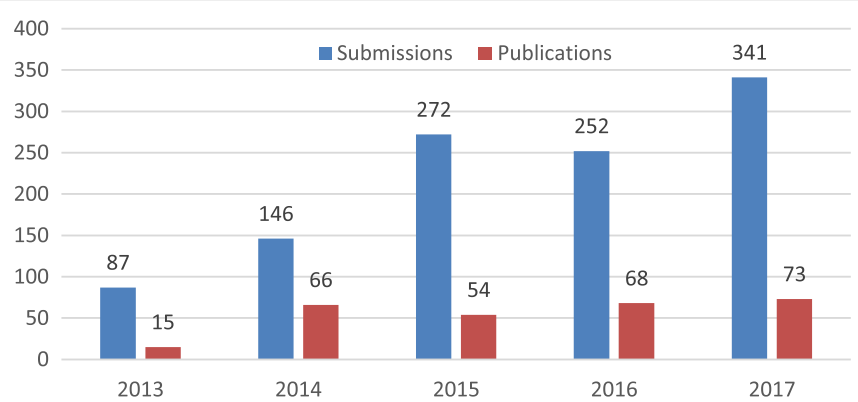

Fig. 2 Submissions and publications

Towards the Second Stage as an international journal, the Journal of Intensive Care shall work hard to contribute to the development of state-of-the-art intensive care and to thereby amend both the short- and long-term outcomes of critically ill patients. Our Editorial Board members earnestly look forward to a number of submissions from all over the world that will further improve the state of intensive care better than today.

\section{Author's contributions}

$\mathrm{HM}$ is fully invloved in writing of the manuscript. The author read and approved the final manuscript.

\section{Competing interests}

The author declares no competing interests.

\section{Publisher's Note}

Springer Nature remains neutral with regard to jurisdictional claims in published maps and institutional affiliations.

Received: 11 February 2018 Accepted: 13 February 2018

Published online: 06 March 2018

Submit your next manuscript to BioMed Central and we will help you at every step:

- We accept pre-submission inquiries

- Our selector tool helps you to find the most relevant journal

- We provide round the clock customer support

- Convenient online submission

- Thorough peer review

- Inclusion in PubMed and all major indexing services

- Maximum visibility for your research

Submit your manuscript at www.biomedcentral.com/submit 